\title{
Biochemical and histopathological endpoints of in vivo cadmium toxicity in Sparus aurata
}

\section{Respuestas bioquímicas e histopatológicas a la toxicidad por cadmio in vivo en Sparus aurata}

\author{
PM Costa*, MH Costa
}

IMAR-Instituto do Mar, Departamento de Ciências e Engenharia do Ambiente, Faculdade de Ciências e Tecnologia da Universidade Nova de Lisboa, 2829-516 Caparica, Portugal.*E-mail: pmcosta@fct.unl.pt

\begin{abstract}
Cadmium $(\mathrm{Cd})$ is a non-essential metal common in water bodies subjected to anthropogenic pollution. Its proven toxicity to aquatic and terrestrial organisms (including humans) has made this metal a subject of particular interest in toxicological studies, especially concerning common coastal fish species that are important marine resources, such as Sparus aurata. In order to establish laboratory tests and biomarker techniques to assess in vivo Cd toxicity in a multilevel (from histological to biochemical) approach, a short-term (48 h) assay was performed using juvenile $S$. aurata injected intraperitoneally with individual Cd dosages (0-8.1 $\mu \mathrm{g} \mathrm{Cd} \mathrm{g}^{-1}$ fish w.w.). The results showed that $\mathrm{Cd}$ causes a fast and pronounced histopathological degeneration of liver tissue and an exponential induction in liver metallothionein-like proteins (MTs) strongly correlated to the injected Cd dosage (Spearman $R=0.97, P<0.01$ ) but not to Cd bioaccumulation or survival time. The relationships between Cd dosage, liver Cd, and liver MT suggested the existence of an absorbed Cd threshold after which the animals were no longer able to regulate and bioaccumulate the metal. This threshold was not dependent on survival time but rather on Cd dosage. The findings also confirmed the suitability of $S$. aurata as a test organism regarding toxicity caused by Cd. Complimentarily, a histological technique using a fluorochrome (acridine orange) to enhance tissue detail is described, as well as a method suitable for the detection of MTs in SDS-PAGE gels with a colloidal Coomassie blue stain.
\end{abstract}

Key words: bioaccumulation, cadmium, histopathology, metallothionein induction, Sparus aurata.

\section{Resumen}

El cadmio $(\mathrm{Cd})$ es un metal no esencial que se encuentra comúnmente en los cuerpos de agua sujetos a contaminación antropogénica. Debido a su toxicidad en organismos acuáticos y terrestres (incluyendo el ser humano) este metal se ha convertido en sujeto de particular interés en los estudios toxicológicos, especialmente en los relacionados con las especies de peces costeros que son importantes recursos marinos, tales como Sparus aurata. A fin de establecer las pruebas de laboratorio y las técnicas de biomarcadores para evaluar la toxicidad de $\mathrm{Cd}$ in vivo con un enfoque múltiple (desde histológico hasta bioquímico), se realizó un ensayo de corta duración ( $48 \mathrm{~h}$ ) con juveniles de $S$. aurata inyectados intraperitonealmente con dosis individuales de $\mathrm{Cd}\left(0-8.1 \mu \mathrm{g} \mathrm{Cd} \mathrm{g}{ }^{-1}\right.$ pez p.h.). Los resultados mostraron que el Cd genera una rápida y pronunciada degeneración histopatológica del tejido hepático y una inducción exponencial de las metalotioneínas (MTs) hepáticas fuertemente correlacionadas con la dosis de Cd inyectada (Spearman $R=0.97, P<0.01$ ) pero no con la bioacumulación de Cd o el tiempo de supervivencia. Las relaciones entre la dosis de $\mathrm{Cd}$, el $\mathrm{Cd}$ hepático y la MT hepática indicaron la existencia de un umbral de absorción de Cd después del cual los animales ya no son capaces de regular y bioacumular este metal. Este umbral no dependió del tiempo de supervivencia, sino más bien de la dosis de Cd. Los resultados también confirmaron la conveniencia de utilizar $S$. aurata como un organismo de prueba para la toxicidad por $\mathrm{Cd}$. De forma complementaria se describe una técnica histológica usando un fluorocromo (naranja de acridina) para intensificar los detalles del tejido, así como un método adecuado para la detección de MTs en geles de SDS-PAGE teñidos con azul de Coomassie coloidal.

Palabras clave: bioacumulación, cadmio, Sparus aurata, histopatología, inducción de metalotioneínas.

\section{Introduction}

Cadmium (Cd) is a non-essential metal that may be found in potentially toxic concentrations in waters and sediments of coastal areas subjected to anthropogenic sources of pollution. Moreover, metal contamination in these areas is affected by physicochemical gradients formed at the sea-freshwater junction (e.g., pH and salinity), which combined with sediment disturbance events may contribute to a release of metals to the water column (Martínez et al. 2006). Cadmium is one of the

\section{Introducción}

El cadmio ( $\mathrm{Cd}$ ) es un metal no esencial que se puede encontrar en concentraciones potencialmente tóxicas en el agua y sedimentos de las zonas costeras sujetas a fuentes antropogénicas de contaminación. Además, la contaminación por metales en estas zonas es afectada por los gradientes fisicoquímicos que se crean en la interfaz entre el agua de mar y el agua dulce (e.g., $\mathrm{pH}$ y salinidad), que en conjunto con los eventos de perturbación sedimentaria pueden contribuir a la 
metals of top concern following point pollution events such as industrial and oil tanker spills. Its presence in the environment and its effects and accumulation in organisms have, for instance, been deeply surveyed in the NW Iberian Peninsula following the Prestige tanker incident (e.g., Férnandez et al. 2006, Prego et al. 2006). Regarding continuous pollution, rivers and estuaries affected by heavy industrial and mining activities are typically problematic areas concerning $\mathrm{Cd}$ contamination. Waeles et al. (2004), for instance, estimated that up to $14 \mathrm{~kg}$ of dissolved, thus highly bioavailable, $\mathrm{Cd}$ are discharged daily from the Loire River (France) to the continental shelf. Audry et al. (2004) found concentrations of dissolved Cd of up to $16.7 \mu \mathrm{g} \mathrm{L}^{-1}$ in another estuarine system in France, even a decade after the shutting down of a mineral ore processing plant that discharged effluents contaminated with $\mathrm{Cd}$. It is noteworthy that the aforesaid concentration is above the chronic toxicity threshold in fish exposed to waterborne $\mathrm{Cd}$ (e.g., Chowdhury et al. 2004).

Since $\mathrm{Cd}$ is a well-known strong toxicant, considerable research has been performed to assess its bioaccumulation and impact on the health of aquatic organisms, especially concerning important marine resources such as the gilthead seabream, Sparus aurata L 1758, a species that represents a valuable catch for coastal fisheries throughout southern Europe and the Mediterranean. This species is often reared in mariculture installations located in estuaries and other enclosed water bodies, potentially of concern in regard to metal contamination. The toxicity of $\mathrm{Cd}$ to organisms is responsible for effects at cellular and tissue levels: it is a known genotoxicant, causing both DNA-strand breakage (leading to mutagenesis and carcinogenesis) and chromosomal clastogenesis (originating micronuclei and other nuclear abnormalities; Risso-de Faverney et al. 2001, Costa and Costa 2007). This metal causes the rupturing of cell and organelle membranes, tissue disaggregation, and neoplasic lesions, and is known to cause abnormal embryogenesis in fish (Jones et al. 2001, Hallare et al. 2005). It triggers a series of different molecular responses, like induction of antioxidative stress enzymes, such as catalase and superoxide dismutase (Žikić et al. 2001), and also induces transcription of glutathione and metallothionein-like proteins that chelate free Cd ions (Singhal et al. 1987, Wormser et al. 1990). The quantification of induction or activity of these responses is frequently employed as a biomarker of Cd contamination.

Metallothioneins (MTs), first described by Margoshes and Vallee (1957) as Cd-binding proteins from horse kidney cortex, are small cytosolic proteins involved in metal storage and detoxification processes. They have about 60 amino acids (none or few of which are aromatic) and a high content of cysteine residues that do not form disulfide bonds and are responsible for sequestering metals. These proteins are very conservative among animal groups and have been widely employed as biomarkers of response to metal exposure, especially to $\mathrm{Cd}$, a known strong MT inducer (reviewed by Romero-Isart and Vašák 2002), in species including S. aurata MT (Tom et al. 1998, 2004; Costa et al. 2008). liberación de metales a la columna de agua (Martínez et al. 2006). El Cd es uno de los metales que causa mayor preocupación después de eventos puntuales de contaminación como los derrames industriales y de buques petroleros. Su presencia en el ambiente y su acumulación y efectos en organismos fueron estudiados a fondo en el noroeste de la Península Ibérica después del incidente del petrolero Prestige (e.g., Férnandez et al. 2006, Prego et al. 2006). En cuanto a la contaminación continua, los ríos y estuarios bajo una fuerte influencia de actividades industriales y mineras son áreas típicamente problemáticas en lo que respecta a la contaminación por Cd. Waeles et al. (2004), por ejemplo, estimaron que diariamente se descargan hasta $14 \mathrm{~kg}$ de Cd disuelto, y por tanto muy biodisponible, del Río Loira (Francia) hacia la plataforma continental. Audry et al. (2004) encontraron concentraciones de $\mathrm{Cd}$ disuelto de hasta $6.7 \mu \mathrm{g} \mathrm{L}^{-1}$ en otro sistema estuarino de Francia, aún después de una década de haber sido clausurada una planta procesadora de minerales que descargaba efluentes contaminados por $\mathrm{Cd}$. Cabe hacer notar que tal concentración se encuentra por arriba del umbral de toxicidad crónica en peces expuestos al Cd transportado por el agua (e.g., Chowdhury et al. 2004).

En vista de la bien sabida toxicidad del Cd, se han llevado a cabo varios estudios para evaluar su bioacumulación y su efecto en la salud de organismos acuáticos, especialmente en los que se consideran importantes recursos marinos como la dorada Sparus aurata L 1758, una especie cuyas pesquerías son importantes en todo el sur de Europa y el Mediterráneo. Esta especie es frecuentemente cultivada en granjas ubicadas en estuarios y otros cuerpos de agua protegidos especialmente susceptibles a la contaminación por metales. En los organismos, la toxicidad del $\mathrm{Cd}$ tiene efectos a nivel celular e histológico, como su efecto genotóxico que genera tanto la rotura de filamentos de ADN (causando mutagénesis y carcinogénesis), como clastogénesis cromosómica (originando micronúcleos y otras anormalidades nucleares; Risso-de Faverney et al. 2001, Costa y Costa 2007). Este metal causa ruptura de membranas de células y organelos, la disgregación de tejidos, lesiones neoplásicas, y anomalías en la embriogénesis de peces (Jones et al. 2001, Hallare et al. 2005). Desencadena diversas respuestas moleculares como la inducción de enzimas antioxidantes como la catalasa y la dismutasa superóxida (Žikić et al. 2001), y la transcripción de proteínas como el glutatión y las llamadas metalotioneínas que quelan los iones libres de Cd (Singhal et al. 1987, Wormser et al. 1990). El nivel de inducción o actividad de estas respuestas se utiliza con frecuencia como un biomarcador de la contaminación por $\mathrm{Cd}$.

Las metalotioneínas (MTs), descritas por primera vez por Margoshes y Vallee (1957) como proteínas enlazantes del Cd en la corteza renal de equinos, son pequeñas proteínas citosólicas involucradas en el almacenamiento de metales y procesos de destoxificación. Tienen alrededor de 60 aminoácidos (ninguno de los cuales son aromáticos) y un alto contenido de residuos de cisteína que no forman puentes disulfito y son responsables del secuestro de metales. Estas proteínas son muy conservativas entre ciertos grupos animales $y$ han sido 
Assessment of histopathologies in fish has long been proposed as a sensitive tool for water quality biomonitoring (Handy et al. 2002). Gills and liver are the most surveyed organs in fish due to their role in apical entry and metabolism of contaminants, respectively. In S. aurata, gill histopathology has already been employed as a biomarker of exposure to environmental pollution (Morales-Caselles et al. 2007), as well as immunohistochemistry of liver CYP1A regarding exposure to organic contaminants (Arellano et al. 2001). Nevertheless, no specific reference information exists for this species regarding histological liver damage induced by $\mathrm{Cd}$.

Environmental variables such as temperature and $\mathrm{pH}$ are known to influence the toxicity of xenobiotics, such as $\mathrm{Cd}$, from biochemical to histopathological endpoints (Carvalho et al. 2004, Hallare et al. 2005). The presence of other contaminants is also known to confound toxicity: $\mathrm{Cr}$, for instance, downregulates MT expression even in the presence of strong MT inducers such as Cd and Zn (Majumder et al. 2003). For these reasons, studies performed on the mechanisms of $\mathrm{Cd}$ toxicity under strict laboratory conditions using isolated contaminants and surveying different classes of biomarkers are of great relevance in order to understand the real effects of a specific xenobiotic.

The main goals of the present study were: (i) to test and establish a range of $\mathrm{Cd}$ contamination biomarkers and laboratory conditions for in vivo assays using $S$. aurata as test organism; (ii) to assess the effects and lethality thresholds of injected $\mathrm{Cd}$ (acute and subacute dosages) in this species to serve as reference for future tests; and (iii) to integrate the various effects of contamination, from biochemical (MT induction and $\mathrm{Cd}$ accumulation in liver) to histological (in hepatic tissue) levels.

\section{Material and methods}

\section{Laboratory assay}

Juvenile hatchery-brood S. aurata from the same cohort $(95.3 \pm 14.6 \mathrm{~mm}$ standard length, $22.5 \pm 11.2 \mathrm{~g}$ total wet weight [w.w.]) were injected intraperitoneally with $500 \mu \mathrm{L}$ of a Cd standard solution (Merck, Darmstadt, Germany) diluted in $50 \mathrm{mM}$ phosphate buffer $(\mathrm{pH}=7.4)$. Three individuals were tested as controls and injected only with buffer. Six others were injected with several $\mathrm{Cd}$ solutions (100-250 $\left.\mu \mathrm{g} \mathrm{Cd} \mathrm{L}^{-1}\right)$. Together with the animals' different body size, these concentrations allowed different individual $\mathrm{Cd}$ dosages to be obtained, within the projected range of 5-10 $\mu \mathrm{g} \mathrm{Cd} \mathrm{g}{ }^{-1}$ fish w.w. Each animal was subjected to a short-term laboratory assay $(48 \mathrm{~h})$ in a 15-L polyvinyl tank, with water recirculation and constant aeration, containing $12 \mathrm{~L}$ of the same water in which the fish were reared. Water temperature was held constant at $18 \pm 1^{\circ} \mathrm{C}$, salinity was $31 \pm 1$, and $\mathrm{pH} 7.6 \pm 0.1$. Photoperiod was set at 12:12 h light:dark. Fish were fed commercial fish pellets (Dibaq, Segovia, Spain) daily. The assay was monitored constantly for mortality, and dead or dying individuals were ampliamente utilizadas como biomarcadores de la respuesta a la exposición a metales, especialmente al $\mathrm{Cd}$, que es un conocido inductor de MTs (revisado por Romero-Isart y Vašák 2002) en especies como S. aurata (Tom et al. 1998, 2004; Costa et al. 2008).

La evaluación de histopatologías en peces es considerada una herramienta útil en el biomonitoreo de la calidad del agua (Handy et al. 2002). En los peces, las branquias y el hígado son los órganos más estudiados debido al papel que juegan en la entrada apical y el metabolismo de los contaminantes, respectivamente. Se ha utilizado la histopatología de las branquias de $S$. aurata como un biomarcador de la exposición a la contaminación ambiental (Morales-Caselles et al. 2007), así como la inmunohistoquímica de CYP1A en su hígado en relación con la exposición a contaminantes orgánicos (Arellano et al. 2001). Sin embargo, no existen referencias específicas para esta especie en cuanto al daño hepático histológico inducido por el $\mathrm{Cd}$.

Es bien conocido que variables ambientales como la temperatura y el $\mathrm{pH}$ afectan la toxicidad de xenobióticos como el $\mathrm{Cd}$, causando desde respuestas bioquímicas hasta histopatológicas (Carvalho et al. 2004, Hallare et al. 2005). La presencia de otros contaminantes también afecta la toxicidad: el $\mathrm{Cr}$, por ejemplo, reduce la expresión de las MTs aun en presencia de fuertes inductores de éstas como el Cd y el $\mathrm{Zn}$ (Majumder et al. 2003). Por estas razones, los estudios de los mecanismos toxicológicos del $\mathrm{Cd}$ bajo estrictas condiciones de laboratorio usando contaminantes aislados y evaluando diferentes clases de biomarcadores resultan de gran importancia para entender los efectos reales de un xenobiótico específico.

Los principales objetivos de este trabajo fueron: (i) probar y establecer el intervalo de los biomarcadores de contaminación por $\mathrm{Cd}$ y las condiciones de laboratorio para los ensayos in vivo usando S. aurata como organismo de prueba; (ii) evaluar los efectos y umbrales de letalidad del Cd inyectado (dosis agudas y subagudas) a esta especie para servir como referencia en pruebas futuras; y (iii) integrar los diversos efectos de contaminación, desde bioquímicos (inducción de MTs y acumulación de $\mathrm{Cd}$ en el hígado) hasta histológicos (en tejido hepático).

\section{Materiales y métodos}

\section{Ensayo de laboratorio}

Se inyectaron, intraperitonealmente, juveniles de $S$. aurata obtenidos de la misma cohorte en un criadero $(95.3 \pm 14.6 \mathrm{~mm}$ de longitud estándar, $22.5 \pm 11.2 \mathrm{~g}$ de peso húmedo [p.h.] total) con $500 \mu \mathrm{L}$ de una solución estándar de Cd (Merck, Darmstadt, Alemania) diluida en tampón de fosfatos $50 \mathrm{mM}(\mathrm{pH}=7.4)$. Se utilizaron tres individuos como controles, los cuales sólo fueron inyectados con tampón. Otros seis individuos fueron inyec-

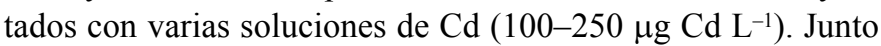
con los diferentes tamaños de los animales, estas concentraciones permitieron obtener diferentes dosis individuales de $\mathrm{Cd}$, con un intervalo proyectado entre 5 y $10 \mu \mathrm{g} \mathrm{Cd} \mathrm{g}^{-1}$ pez p.h. 
immediately removed from the tanks and processed for bioaccumulation and biomarker analyses.

\section{Liver MT and Cd determinations}

Liver portions were homogenized in cold Tris- $\mathrm{HCl} 0.02 \mathrm{M}$ buffer (pH 8.6) and centrifuged for $1 \mathrm{~h}$ at $30,000 \mathrm{~g}\left(4^{\circ} \mathrm{C}\right)$. The supernatant (cytosol) was then heated at $80^{\circ} \mathrm{C}$ for $10 \mathrm{~min}$ to denaturate non-heat resistant proteins and centrifuged $(1 \mathrm{~h}$ at $30,000 \mathrm{~g}, 4^{\circ} \mathrm{C}$ ) to precipitate most of the non-heat resistant and high molecular weight proteins. The determination of MTs from the heat-treated cytosols was performed by differential pulse polarography (DPP), using a static mercury drop electrode (SMDE) with a 694 stand and 693 processor from Metrohm (Herisau, Switzerland). The electrode system consisted of a mercury capillary working electrode, an $\mathrm{Ag} / \mathrm{AgCl}$ reference electrode, and a platinum auxiliary electrode. The supporting electrolyte $\left(1 \mathrm{M} \mathrm{NH}_{4} \mathrm{Cl}, 1 \mathrm{M} \mathrm{NH}_{4} \mathrm{OH}\right.$, and $2 \mathrm{mM}$ $\left.\left[\mathrm{Co}\left(\mathrm{NH}_{3}\right)_{6}\right] \mathrm{Cl}_{3}\right)$ was prepared weekly and stored at $4^{\circ} \mathrm{C}$ (Palecek and Pechan 1971). In the absence of a commercial purified fish MT, rabbit MT forms I and II (Sigma, St. Louis, MO, USA) was used for standard addition. The MT extraction and determination by DPP-SMDE followed the procedure described by Costa et al. (2008), adapted from Bebianno and Langston (1989). Results are given in mg MT-equivalent $\mathrm{g}^{-1}$ liver dry weight (d.w.).

The presence of a protein compatible with S. aurata MT was determined by sodium dodecyl sulphate polyacrylamide gel electrophoresis (SDS-PAGE) of heat-treated cytosols and rabbit-MT standards. MT is difficult to visualize in gels due to a series of factors such as the near absence of aromatic amino acids, to which Coomassie brilliant blue selectively binds to, and the protein's trend to form polymers in gels (Suzuki et al. 1998), a phenomenon that typically causes a faint protein smear instead of a clear band. An effective method was achieved to detect MT bands without overblotting the cytosolic protein lanes as when silver nitrate is employed. Gels were adapted from Laemmli (1970) and consisted of a 5\% acrylamide stacking gel (in $0.5 \mathrm{M}$ Tris- $\mathrm{HCl}$ buffer, $\mathrm{pH}=6.8$ ) and a $15 \%$ acrylamide running gel (in $1.5 \mathrm{M}$ Tris- $\mathrm{HCl}$ buffer, $\mathrm{pH}=$ 8.8 ), both with $10 \%$ SDS. Higher percentage of acrylamide (15-19\%) enhances resolution of small proteins such as MTs. Aliquots of heat-treated cytosols were further heated at $100^{\circ} \mathrm{C}$ during $5 \mathrm{~min}$ in sample buffer containing $\beta$-mercaptoethanol as reducing agent prior to gel loading in order to promote MT depolymerization. Electrophoresis was run at slow speed $(130 \mathrm{~V})$ to promote band resolution, in 3\% w/v Tris, $14.4 \% \mathrm{w} /$ $\mathrm{v}$ glycine, and $1 \% \mathrm{w} / \mathrm{v}$ SDS running buffer. After rinsing with Milli-Q water to wash off all SDS, gels were fixed in $50 \% \mathrm{v} / \mathrm{v}$ methanol and $2 \% \mathrm{v} / \mathrm{v}$ phosphoric acid (85\%) until bromphenol blue disappeared, rinsed again, and stained for $24 \mathrm{~h}$ by the colloidal Coomassie silver blue method (Candiano et al. 2004). This method provides an intermediate resolution between silver staining and classical colloidal Coomassie brilliant blue staining. The staining solution contained $20 \% \mathrm{v} / \mathrm{v}$ methanol, $10 \% \mathrm{v} / \mathrm{v}$ phosphoric acid (85\%), $10 \% \mathrm{w} / \mathrm{v}$ ammonium
Cada animal fue sometido a un ensayo de corta duración (48 h) en un tanque de polivinilo de $15 \mathrm{~L}$ de capacidad, con recirculación de agua y aireación constante, conteniendo $12 \mathrm{~L}$ de la misma agua en la cual fueron criados. La temperatura se mantuvo constante a $18 \pm 1^{\circ} \mathrm{C}$, la salinidad fue $31 \pm 1$ y el pH $7.6 \pm$ 0.1 . Se usó un fotoperiodo de 12:12 h luz:oscuridad. Los peces fueron alimentados diariamente con ración para peces (Dibaq, Segovia, España). La mortandad fue monitoreada constantemente durante el ensayo, retirando inmediatamente los individuos muertos o moribundos de los tanques y procesándolos para los análisis de bioacumulación y biomarcadores.

\section{Determinaciones de las MTs y el Cd en hígado}

Se homogeneizaron porciones de hígado en tampón frío Tris- $\mathrm{HCl} 0.02 \mathrm{M}(\mathrm{pH}$ 8.6) y se centrifugaron durante $1 \mathrm{~h}$ a $30,000 \mathrm{~g}\left(4^{\circ} \mathrm{C}\right)$. Posteriormente se calentó el sobrenadante (citosol) a $80^{\circ} \mathrm{C}$ por 10 min para desnaturalizar las proteínas térmicamente inestables y se centrifugó $\left(1 \mathrm{~h} \mathrm{a} 30,000 \mathrm{~g}, 4^{\circ} \mathrm{C}\right)$ para precipitar la mayoría de las proteínas térmicamente inestables y de alto peso molecular. La determinación de las MTs en los citosoles tratados térmicamente se realizó mediante polarografía de pulso diferencial con un electrodo de gota de mercurio (DPP-SMDE, por sus siglas en inglés) con una base 694 y un procesador 693 de Metrohm (Herisau, Suiza). El sistema de electrodos consistió en un electrodo capilar de mercurio de trabajo, un electrodo de referencia de $\mathrm{Ag} / \mathrm{AgCl}$ y un electrodo de platino. El electrolito soporte $\left(\mathrm{NH}_{4} \mathrm{Cl} 1 \mathrm{M}\right.$, $\mathrm{NH}_{4} \mathrm{OH} 1 \mathrm{M}$, y $\left.\left[\mathrm{Co}\left(\mathrm{NH}_{3}\right)_{6}\right] \mathrm{Cl}_{3} 2 \mathrm{mM}\right)$ fue preparado semanalmente y almacenado a $4^{\circ} \mathrm{C}$ (Palecek y Pechan 1971). En ausencia de una MT comercial de pez, se utilizó MT de conejo (formas I y II, Sigma, St. Louis, MO, EUA) como estándar. La extracción y la determinación de las MTs mediante DPPSMDE se realizaron siguiendo el procedimiento descrito por Costa et al. (2008), adaptado de Bebianno y Langston (1989). Los resultados se presentan en mg MT-equivalente $\mathrm{g}^{-1}$ de hígado peso seco (p.s.).

La presencia de una proteína compatible con la MT de $S$. aurata se determinó mediante electroforesis en gel de poliacrilamida con dodecil sulfato de sodio (SDS-PAGE, por sus siglas en inglés) de la fracción citosólica tratada térmicamente y los estándares de MT de conejo. Es difícil visualizar las MTs en geles debido a una serie de factores como son la casi nula presencia de aminoácidos aromáticos, a los cuales se une selectivamente el azul brillante de Coomassie, y la tendencia de las proteínas a formar polímeros en geles (Suzuki et al. 1998), un fenómeno que típicamente causa una mancha de proteínas tenue en vez de una banda clara. Se logró un método efectivo para detectar las bandas de MTs sin manchar los carriles de las proteínas citosólicas como sucede cuando se usa el nitrato de plata. Los geles de acrilamida se adaptaron de acuerdo con Laemmli (1970) y consistieron de un gel de apilamento al 5\% (en tampón Tris- $\mathrm{HCl} 0.5 \mathrm{M}, \mathrm{pH}=6.8$ ) y un gel de separación al $15 \%$ (en tampón Tris- $\mathrm{HCl} 1.5 \mathrm{M}, \mathrm{pH}=8.8$ ), ambos con $10 \%$ de SDS. Un mayor porcentaje de acrilamida (15-19\%) 
sulphate, and $0.12 \% \mathrm{w} / \mathrm{v}$ Coomassie brilliant blue G250. The MT molecular weight was determined by comparison of migration distances with a pre-stained broad-range protein ladder (ref. 161-0318, from Bio-Rad, Hercules, CA, USA), using the Quantity One 4.2.2 software (Bio-Rad, Hercules, CA, USA).

Bioaccumulation of $\mathrm{Cd}$ was determined from oven-dried (five days at $80^{\circ} \mathrm{C}$ ) liver samples digested with $\mathrm{HNO}_{3}$ and $\mathrm{H}_{2} \mathrm{O}_{2}$ in TFE canisters (Clesceri et al. 1999). The determination of $\mathrm{Cd}$ was performed by differential pulse anodic stripping voltammetry (DPASV) with a hanging mercury drop electrode (HMDE), using the aforesaid voltammetric apparatus. The supporting electrolyte consisted of $1 \mathrm{M}$ acetate buffer $(\mathrm{pH}=4.6)$. A standard addition method was employed for $\mathrm{Cd}$ quantification, using a $\mathrm{CdCl}_{2}$ solution (Merck, Darmstadt, Germany) as standard. Dogfish liver reference material (DOLT-3, NRCCNRC, Canada) was digested using the same procedure and Cd was determined by DPASV-HMDE to control the precision and accuracy of the procedure, and the values obtained were within the certified range. Results are presented in $\mu \mathrm{g} \mathrm{Cd} \mathrm{g}^{-1}$ liver d.w.

\section{Histological analysis}

Liver portions were fixed in Bouin-Hollande solution for $48 \mathrm{~h}$, washed in distilled water, dehydrated in a progressive series of ethanol, and impregnated with paraffin (xylene was used for intermediate impregnation). Paraffin-embedded sections $(2-\mu \mathrm{m}$ thick) were stained with haematoxylin and eosin (HE) after deparaffination in xylene and rehydration, and afterwards mounted with DPX resinous medium (BDH, Poole, UK). Sample preparation for histological analyses essentially followed Martoja and Martoja (1967). Paraffin-embedded sections (2- $\mu \mathrm{m}$ thick) were prepared as abovementioned prior to staining with acridine orange (AO), a fluorochrome that binds selectively to nucleic acids, which was employed to enhance the contrast of cellular structures such as nuclei and endoplasmatic reticuli. The AO staining solution was prepared with $0.1 \mathrm{~g} \mathrm{~L}^{-1}$ AO base (Sigma, St. Louis, MO, USA; maximum absorbance $488 \mathrm{~nm}$ ) in distilled water with $1 \% \mathrm{v} / \mathrm{v}$ acetic acid. Slides were stained with $\mathrm{AO}$ solution for $30 \mathrm{~min}$ and mounted in DPX after a brief rinse with $0.5 \% \mathrm{v} / \mathrm{v}$ glacial acetic acid in absolute ethanol, followed by $1 \mathrm{~min}$ in absolute ethanol and $1 \mathrm{~min}$ in xylene. All steps from staining onwards (inclusively) were performed using opaque Hellendahl jars to prevent the loss of fluorescence.

Slides were qualitatively analyzed for hepatic lesions with bright-field illumination for HE staining and with ultraviolet light for AO staining, using a BX50 microscope adapted for epifluorescence with a U-ULH $100 \mathrm{~W}$ mercury high-pressure bulb and a U-MWB fluorescein filter (Olympus, Tokyo, Japan).

\section{Statistical analyses}

Data were analyzed using linear regression models, employing the $r^{2}$ statistic to assess goodness-of-fit of graphical incrementa la resolución de proteínas pequeñas como las MTs. Se calentaron nuevamente las alícuotas de los citosoles tratados térmicamente a $100^{\circ} \mathrm{C}$ durante 5 min en un tampón que contenía $\beta$-mercaptoetanol como agente reductor, antes de agregar los geles, para promover la despolimerización de las MTs. La electroforesis se efectuó a baja velocidad $(130 \mathrm{~V})$ para fomentar la resolución de bandas, en un tampón de separación de $3 \%(\mathrm{p} / \mathrm{v})$ de Tris, $14.4 \%(\mathrm{p} / \mathrm{v})$ de glicina y $1 \%(\mathrm{p} / \mathrm{v})$ de SDS. Después de enjuagar con agua Milli-Q para quitar todo el SDS, los geles se fijaron en $50 \%(\mathrm{v} / \mathrm{v})$ de metanol y $2 \%(\mathrm{v} / \mathrm{v})$ de ácido fosfórico (85\%) hasta desaparecer el azul de bromofenol, se volvieron a enjuagar y se tiñieron durante $24 \mathrm{~h}$ con el método de plata azul de Coomassie coloidal (Candiano et al. 2004). Este método proporciona una resolución intermedia entre la tinción con plata y la tinción clásica con el azul brillante de Coomassie coloidal. La solución de tinción consistió en $20 \%(\mathrm{v} / \mathrm{v})$ de metanol, $10 \%(\mathrm{v} / \mathrm{v})$ de ácido fosfórico $(85 \%), 10 \%(\mathrm{p} / \mathrm{v})$ de sulfato de amonio y $0.12 \%(\mathrm{p} / \mathrm{v})$ de azul brillante de Coomassie G250. El peso molecular de las MTs se determinó mediante la comparación de las distancias de migración con una escala de proteínas preteñida de amplio intervalo (ref. 161-0318, de Bio-Rad, Hercules, CA, EUA), usando la paquetería Quantity One 4.2.2 (Bio-Rad, Hercules, CA, EUA).

La bioacumulación de $\mathrm{Cd}$ se determinó usando muestras de hígado secadas al horno (cinco días a $80^{\circ} \mathrm{C}$ ) y digeridas con $\mathrm{HNO}_{3}$ y $\mathrm{H}_{2} \mathrm{O}_{2}$ en botes de TFE (Clesceri et al. 1999). La determinación del $\mathrm{Cd}$ se realizó mediante voltametría de redisolución anódica de pulso diferencial con un electrodo de gota colgante de mercurio (DPASV-HMDE, por sus siglas en inglés), usando el aparato voltamétrico antes mencionado. El electrolito soporte consistió en tampón de acetato $1 \mathrm{M}$ $(\mathrm{pH}=4.6)$. Se empleó un método de adición estándar para la cuantificación del $\mathrm{Cd}$, usando una solución de $\mathrm{CdCl}_{2}$ (Merck, Darmstadt, Alemania) como estándar. Para controlar la exactitud y la precisión del procedimiento, se digirió material de referencia de hígado de pez perro (DOLT-3, NRC-CNRC, Canadá) utilizando el mismo procedimiento y se determinó el $\mathrm{Cd}$ por DPASV-HMDE, resultando los valores obtenidos dentro del intervalo certificado. Los resultados se presentan en $\mu \mathrm{g} \mathrm{Cd} \mathrm{g}^{-1}$ hígado p.s.

\section{Análisis histológico}

Se fijaron porciones de hígado en una solución de BouinHollande por $48 \mathrm{~h}$, y se lavaron con agua destilada, se deshidrataron en una serie progresiva de etanol y se impregnaron con parafina (se utilizó xileno para una impregnación intermedia). Las secciones incluidas en parafina $(2 \mu \mathrm{m}$ de espesor) fueron teñidas con hematoxilina y eosina (HE) después de la desparafinación en xileno y la rehidratación, y posteriormente fueron montadas con medio resinoso DPX (BDH, Poole, RU). La preparación de las muestras para los análisis histológicos esencialmente se realizó de acuerdo con Martoja y Martoja (1967). Se prepararon secciones incluidas en parafina ( $2 \mu \mathrm{m}$ de espesor) según lo descrito anteriormente antes de la tinción con 
functions, and by Spearman's rank-order correlation $R$ statistic. Regressions where $r^{2}<0.5$ were disregarded and the significance level for correlations was set at $\alpha=0.05$. Statistics were performed with Statistica 6 (Statsoft, Tulsa, OK, USA), after Sheskin (2000).

\section{Results}

\section{Lethality thresholds, MT induction, and Cd accumulation}

All control individuals survived the assay but only two animals injected with $\mathrm{Cd}$ survived the entire duration of the assay. Despite one individual having survived a dosage of $8.1 \mu \mathrm{g} \mathrm{Cd} \mathrm{g}^{-1}$ fish w.w., it is apparent that a possible survival time threshold for at least $48 \mathrm{~h}$ after injection may be set at dosages between 4 and $5 \mu \mathrm{g} \mathrm{Cd} \mathrm{g}^{-1}$ fish w.w. A better fit regression model was found between liver MT concentration and injected Cd dosages than between liver MT and Liver Cd. The first case showed the existence of a strong exponential relationship between liver MT and injected Cd dosages (fig. 1a), whereas MT $\times$ liver Cd (fig. 1b) fitted better to a negative second order polynomial model. No significant regression $\left(r^{2}<\right.$ 0.5 ) was found regarding liver $\mathrm{Cd} \times \mathrm{Cd}$ dosage. This showed that liver $\mathrm{Cd}$ levels did not increase with dosage and were too variable to be able to obtain a clear trend. In accordance with the regression results, a strong correlation was found between injected Cd dosages and liver MT (Spearman $R=0.97, P<$ $0.01)$. Conversely, no significant correlation was observed between MT and liver Cd $(P>0.05)$, which is in accordance with the fact that liver MT did not increase at higher levels of bioaccumulated $\mathrm{Cd}$. No significant correlations were found between the injected $\mathrm{Cd}$ dosages and liver $\mathrm{Cd}$, or between survival time and the variables: liver $\mathrm{MT}$, accumulated $\mathrm{Cd}$, and injected $\mathrm{Cd}$ dosage $(P>0.05)$.

The MT $\times$ liver $\mathrm{Cd}$ model showed an inflexion point that marked the threshold after which the liver does not seem capable of regulating $\mathrm{Cd}$ by inducing MT biosynthesis. Regarding MT induction, there was a notorious decrease in naranja de acridina (NA), un fluorocromo que se une selectivamente a los ácidos nucleicos y que se utilizó para incrementar el contraste de estructuras celulares tales como núcleos y retículos endoplasmáticos. Se preparó la solución de tinción de NA usando $0.1 \mathrm{~g} \mathrm{~L}^{-1}$ NA base (Sigma, St. Louis, MO, EUA; máxima absorbancia a $488 \mathrm{~nm}$ ) en agua destilada con $1 \%(\mathrm{v} / \mathrm{v})$ de ácido acético. Las placas fueron teñidas con la solución de NA durante 30 min y montadas en DPX después de un breve enjuague con $0.5 \%(\mathrm{v} / \mathrm{v})$ de ácido acético glacial en etanol absoluto, seguido por $1 \mathrm{~min}$ en etanol absoluto y $1 \mathrm{~min}$ en xileno. Todos los pasos a partir de la tinción (incluida ésta) se llevaron a cabo usando recipientes opacos tipo Hellendahl para prevenir la pérdida de fluorescencia.

Se analizaron cualitativamente las lesiones hepáticas sobre las placas con iluminación de campo brillante para la tinción con HE y con luz ultravioleta para la tinción con NA, usando un microscopio BX50 adaptado para epifluorescencia con un foco de mercurio de alta presión de $100 \mathrm{~W}$ U-ULH y un filtro de fluoresceína U-MWB (Olympus, Tokio, Japón).

\section{Análisis estadísticos}

El análisis de los datos se realizó con modelos de regresión lineal, usando el estadístico $r^{2}$ para evaluar la bondad de ajuste de las funciones gráficas, y el estadístico $R$ de la correlación de rangos de Spearman. No se consideraron las regresiones donde $r^{2}<0.5$ y se estableció el nivel de significancia para las correlaciones en $\alpha=0.05$. Los cálculos estadísticos se realizaron con la paquetería Statistica 6 (Statsoft, Tulsa, OK, EUA), de acuerdo con Sheskin (2000).

\section{Resultados}

\section{Umbrales letales, inducción de MTs y acumulación de Cd}

Todos los individuos controles sobrevivieron el experimento pero solamente dos animales inyectados con $\mathrm{Cd}$ sobrevivieron hasta el final de la prueba. A pesar de que un
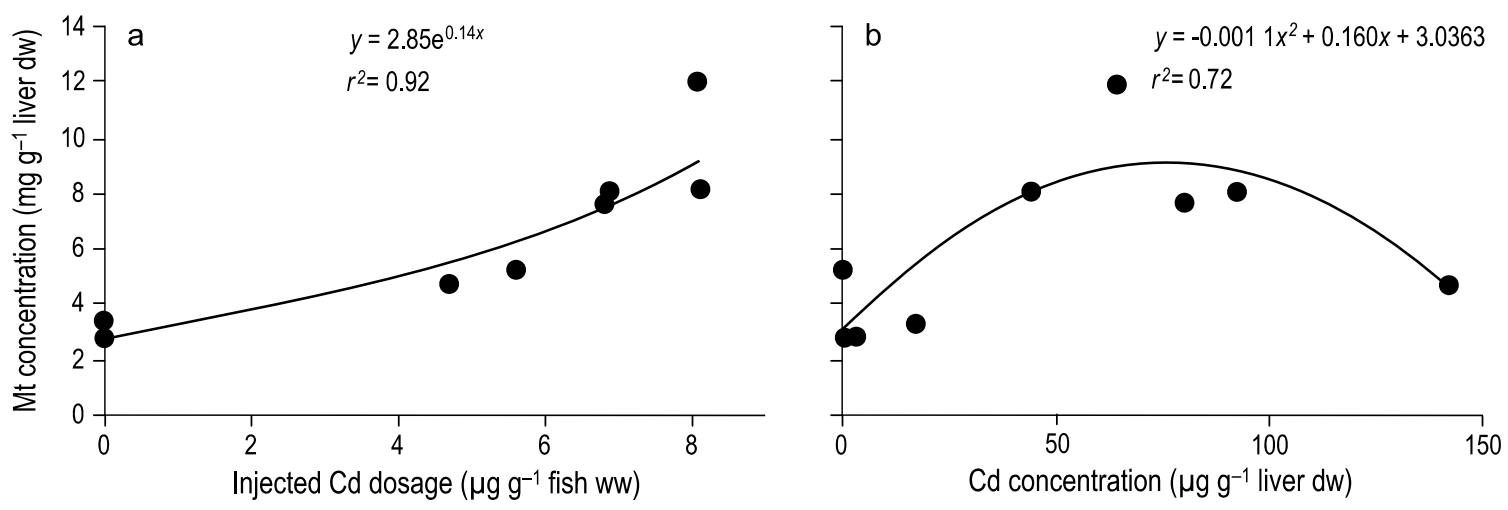

Figure 1. Best fit regression models between significantly correlated variables: (a) liver MT $\times$ injected Cd dosage, and (b) liver MT $\times$ liver Cd. Figura 1. Modelos de regresión de mejor ajuste entre las variables correlacionadas significativamente: (a) MT hepática $\times$ dosis de Cd inyectada y (b) MT hepática $\times$ Cd hepático. 
liver MT synthesis after the $\mathrm{Cd}$ accumulation threshold value of $\approx 80 \mu \mathrm{g} \mathrm{g}^{-1}$ liver d.w.

The SDS-PAGE gels showed a dim but consistent band in heat-treated cytosol samples, with approximately the same molecular weight as the rabbit liver MT used as standard, that may be assigned to $S$. aurata MT (fig. 2). The estimated molecular weight for the dimeric form of MT was $15 \pm 1 \mathrm{kDa}$ for both rabbit standard and S. aurata MT.

\section{Histopathology}

Control individuals showed a normal structure of hepatic tissue: hepatocytes were well individualized and polyedric in shape, with conspicuous constant-sized nuclei with individualized nucleoli. The liver exhibited inclusions of pancreatic

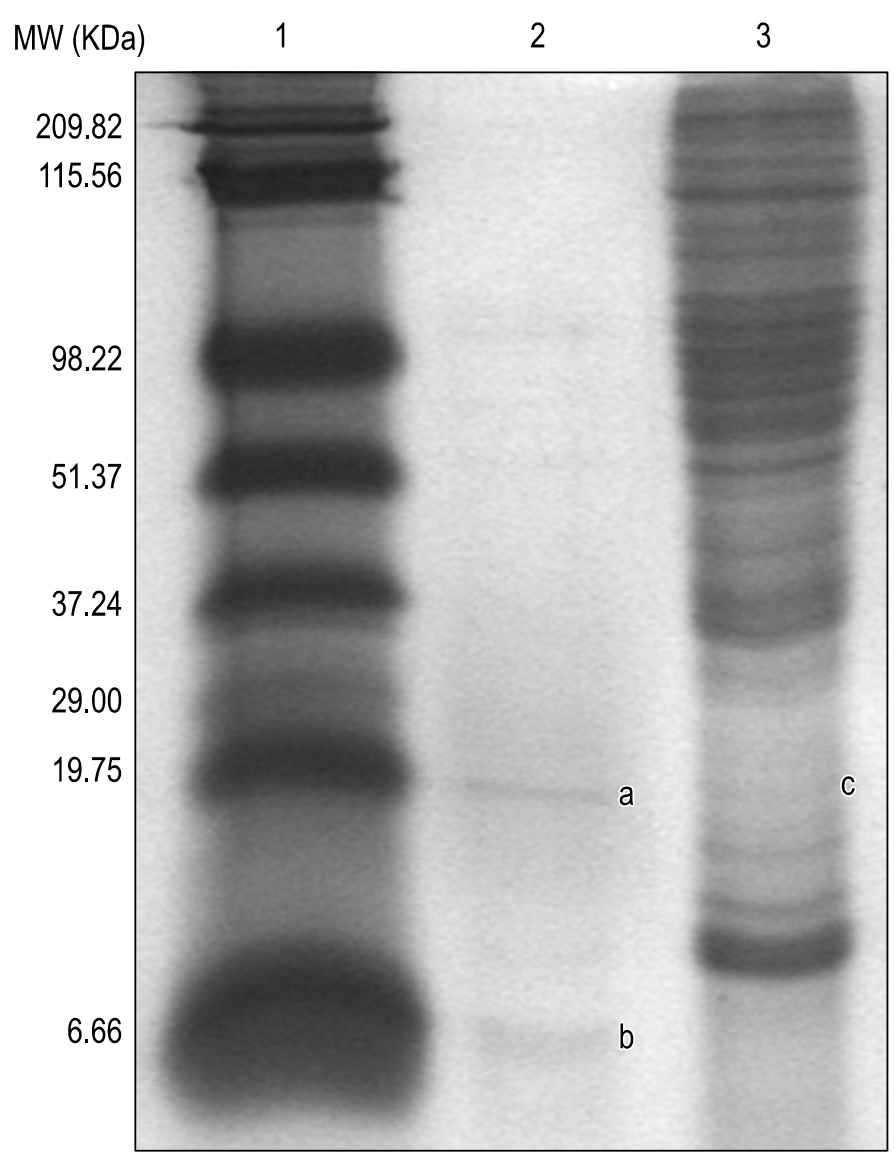

Figure 2. SDS-PAGE gel of heat-treated cytosol: lane 1 = broad-range MW standard, lane 2 = rabbit MT standard, and lane $3=$ heat-treated Sparus aurata cytosol (from a control individual); $a=$ dimeric form of rabbit MT (15 $\pm 1 \mathrm{kDa}), \mathrm{b}=$ monomeric form of rabbit MT (6 $\pm 1 \mathrm{kDa})$, and $\mathrm{c}=$ dimeric form of $S$. aurata MT (15 $\pm 1 \mathrm{kDa})$.

Figura 2. Gel de SDS-PAGE de un citosol tratado térmicamente: carril $1=$ estándar de MT de intervalo amplio, carril 2 = estándar de MT de conejo, y carril 3 = citosol tratado térmicamente de Sparus aurata (de un individuo control); $a$ = forma dimérica de MT de conejo (15 $\pm 1 \mathrm{kDa}), \mathrm{b}=$ forma monomérica de MT de conejo ( $6 \pm 1 \mathrm{kDa})$, y c = forma dimérica de MT de S. aurata $(15 \pm 1 \mathrm{kDa})$. individuo sobrevivió una dosis de $8.1 \mu \mathrm{g} \mathrm{Cd} \mathrm{g}^{-1}$ pez p.h., es posible establecer un umbral de tiempo de supervivencia de por lo menos $48 \mathrm{~h}$ después de la inyección a dosis entre 4 y $5 \mu \mathrm{g} \mathrm{Cd} \mathrm{g}^{-1}$ pez p.h. Se obtuvo un mejor ajuste del modelo de regresión entre la concentración de MT hepática y las dosis inyectadas de Cd que entre la MT hepática y el Cd hepático. El primer caso mostró una fuerte relación exponencial entre la MT hepática y las dosis inyectadas de Cd (fig. 1a), mientras que MT $\times \mathrm{Cd}$ hepático (fig. 1b) presentó mejor ajuste a un modelo polinomial negativo de segundo orden. No se encontró una regresión significativa $\left(r^{2}<0.5\right)$ en lo que respecta a la dosis $\mathrm{Cd} \times \mathrm{Cd}$ hepática. Esto mostró que los niveles de $\mathrm{Cd}$ en el hígado no incrementaron con la dosis, y que fueron demasiado variables para poder observar una tendencia clara. De acuerdo con los resultados de la regresión, se encontró una fuerte correlación entre las dosis inyectadas de Cd y la MT hepática (Spearman $R=0.97, P<0.01$ ). Por lo contrario, no se observó una correlación significativa entre MT y Cd hepático $(P>0.05)$, lo que concuerda con que la MT hepática no incrementó a mayores niveles del Cd bioacumulado. No se encontraron correlaciones significativas entre las dosis inyectadas de Cd y el Cd hepático, ni entre el tiempo de supervivencia y las variables MT hepática, $\mathrm{Cd}$ acumulado $\mathrm{y}$ dosis inyectada de $\mathrm{Cd}$ $(P>0.05)$.

El modelo MT $\times \mathrm{Cd}$ hepático mostró un punto de inflexión después de cuyo umbral el hígado no parece poder regular el $\mathrm{Cd}$ induciendo la biosíntesis de MTs. En cuanto a la inducción de MTs, hubo una notable disminución en la síntesis de MT hepática después del umbral de acumulación de $\mathrm{Cd}$ de $\approx 80 \mu \mathrm{g} \mathrm{g}^{-1}$ hígado p.s.

Los geles de SDS-PAGE mostraron una banda tenue pero consistente en las muestras de los citosoles tratados térmicamente, con aproximadamente el mismo peso molecular que la MT de conejo usada como estándar, el cual se puede asignar a la MT de S. aurata (fig. 2). El peso molecular estimado para la forma dímera de MT fue $15 \pm 1 \mathrm{kDa}$ tanto para la MT de conejo como para la de $S$. aurata.

\section{Histopatología}

Los individuos controles mostraron una estructura normal en su tejido hepático: los hepatocitos se observaron bien diferenciados y de forma poliédrica, con núcleos conspícuos y de tamaño constante con nucléolos individuales. El hígado mostró inclusiones de tejido pancreático alrededor de las ramas de la vena porta hepática y muchos sinusoides (fig. 3).

Los individuos inyectados con $\mathrm{Cd}$ mostraron una degradación consistente y muy pronunciada del tejido hepático que aumentó progresivamente con la dosis de $\mathrm{Cd}$, independientemente del tiempo de supervivencia (fig. 4). El daño más evidente fue la degeneración de los hepatocitos, los cuales perdieron su forma celular y cuya membrana plasmática se rompió. Las secciones de hígado también presentaron grandes zonas de necrosis en las que la organización del tejido ya no era perceptible, especialmente en los individuos inyectados con 

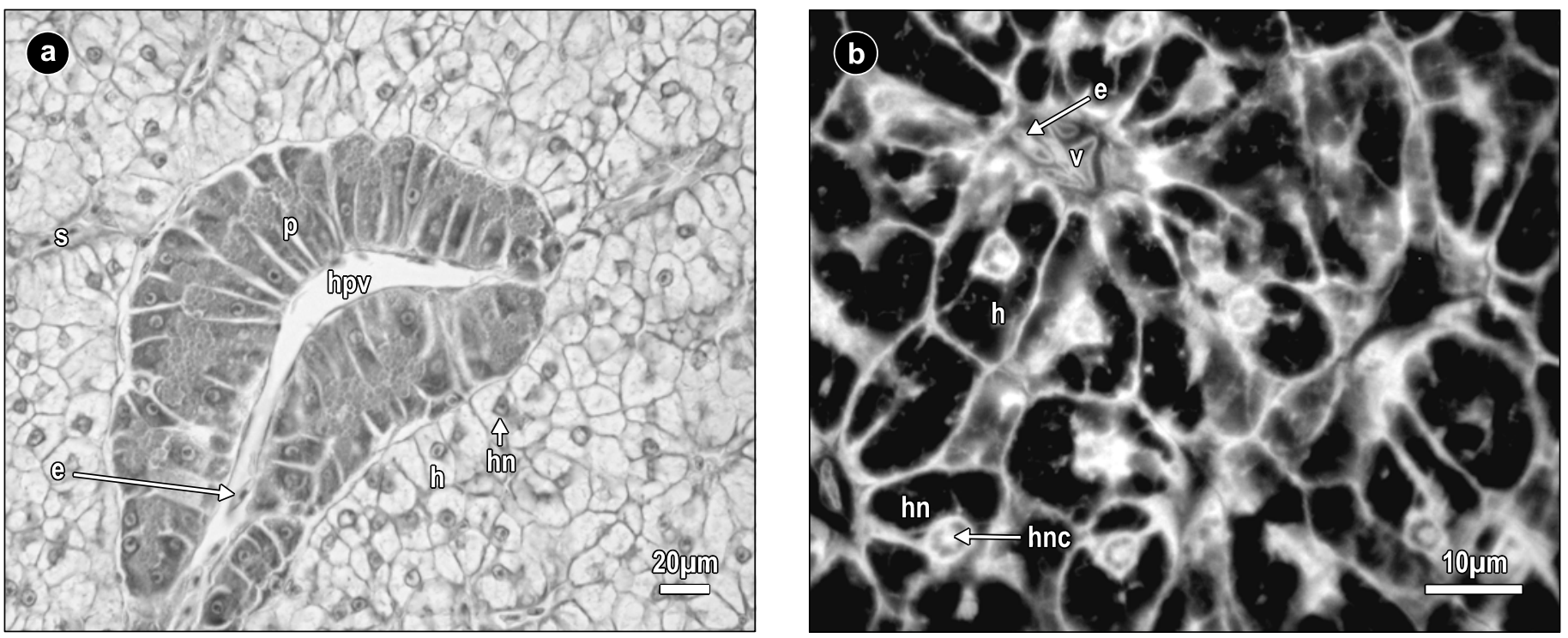

Figure 3. Normal histological structure of the liver of Sparus aurata (control individual): (a) haematoxylin-eosin staining $(\times 400)$, and (b) acridine orange staining (× 1000). Erythrocyte in blood vessel $(\mathrm{e})$, hepatocyte $(\mathrm{h})$, hepatocyte nucleus (hn), hepatocyte nucleolus (hnc), hepatic portal vein branch (hpv), pancreatic tissue (p), sinusoid (s), and venule (v).

Figura 3. Estructura histológica normal del hígado de Sparus aurata (individuo control): (a) tinción con hematoxilina y eosina (× 400) y (b) tinción con naranja de acridina ( $\times 1000)$. Eritrocito en vaso sanguíneo (e), hepatocito (h), núcleo de hepatocito (hn), nucleolo de hepatocito (hnc), rama de la vena porta hepática (hpv), tejido pancreático (p), sinusoide $(\mathrm{s})$, y vénula (v).
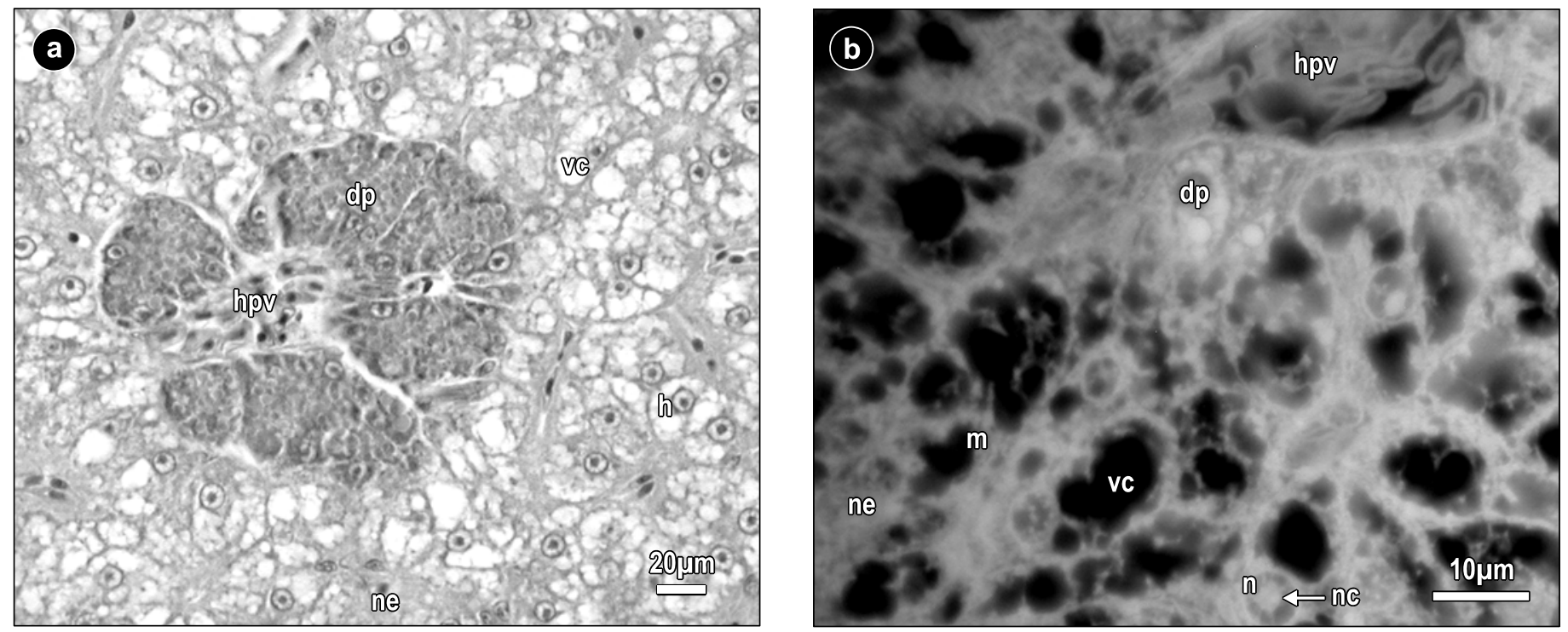

Figure 4. Degenerating hepatic tissue of Sparus aurata (Cd-injected individual surviving after $48 \mathrm{~h})$ : (a) haematoxylin-eosin staining ( $\times 400)$, and (b) acridine orange staining $(\times 1000)$. Degenerative pancreatic tissue $(\mathrm{dp})$, hepatocyte $(\mathrm{h})$, hepatic portal vein branch (hpv), rupturing cellular membrane $(\mathrm{m})$, hepatocyte nucleus (n), hepatocyte nucleolus (hnc), necrotic tissue (ne), and vacuole resulting from fatty degeneration (lipidosis) (vc).

Figura 4. Tejido hepático de Sparus aurata mostrando degeneración (individuo sobreviviendo después de 48 h de ser inyectado con Cd): (a) tinción con hematoxilina y eosina $(\times 400)$ y $(b)$ tinción con naranja de acridina (× 1000). Tejido pancreático degenerativo (dp), hepatocito (h), rama de la vena porta hepática (hpv), membrana celular rota (m), núcleo de hapatocito (n), nucleolo de hepatocito (hnc), tejido necrótico (ne), y vacuola resultando de la degeneración grasa (lipidosis) (vc).

tissue surrounding the branches of the hepatic portal vein and many sinusoids (fig. 3).

The Cd-injected individuals exhibited a consistent and very pronounced degradation of hepatic tissue that increased las mayores dosis de $\mathrm{Cd}\left(>6 \mu \mathrm{g} \mathrm{Cd} \mathrm{g}{ }^{-1}\right.$ pez p.h.). Como era de esperarse, el tejido pancreático se tiñó intensamente con la NA, ya que el fluorocromo se une particularmente al ácido nucleico y, por tanto, el retículo endoplasmático, rugoso y denso, típico 

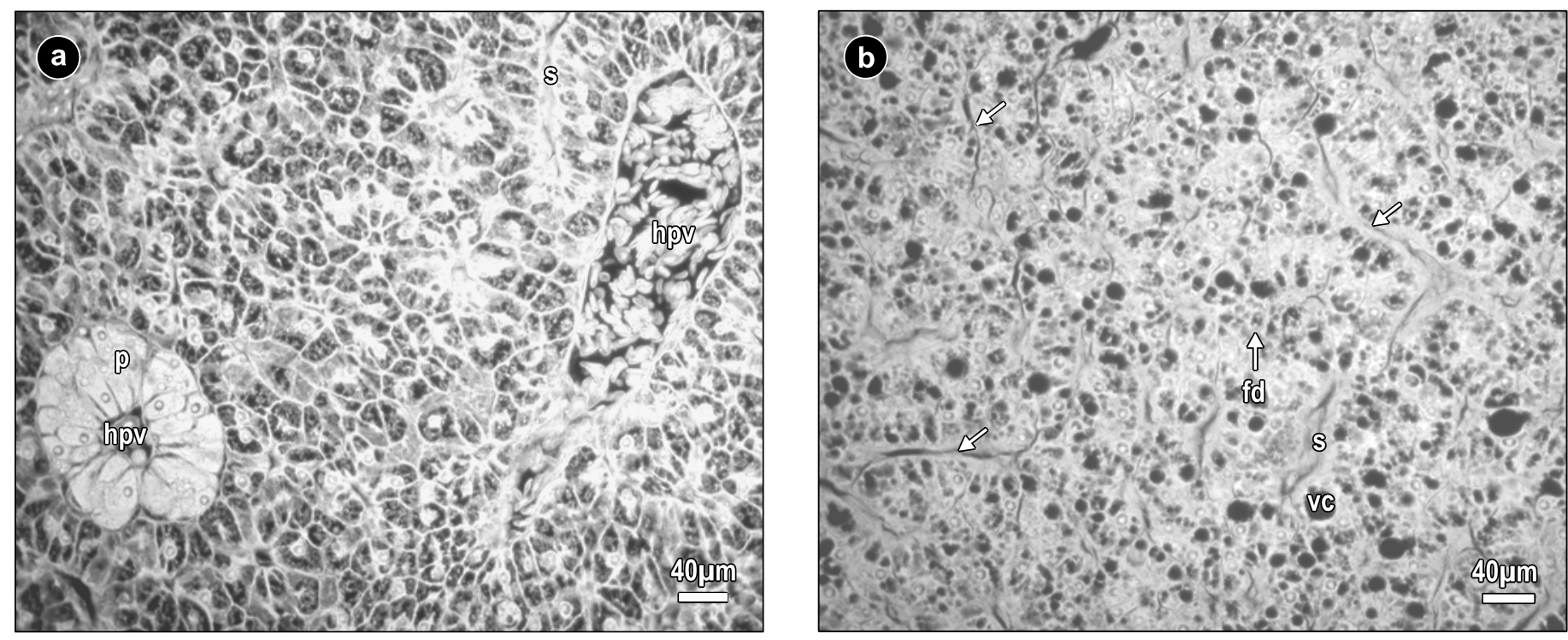

Figure 5. General structure of Sparus aurata liver (acridine orange, $\times 400$ ): (a) normal hepatic tissue from a control individual, and (b) damaged liver from a Cdinjected individual (survival time <24 h). Fatty degeneration (lipidosis) exhibited as an aggregate of small vacuoles (fd), hepatic portal vein branch (hpv), sinusoid (s), normal pancreatic tissue exhibiting the highly fluorescent cytoplasm of acinar cells (p), and fatty degeneration demonstrated as a large vacuole (vc). Arrows indicate structural splitting of tissue.

Figura 5. Estructura general del hígado de Sparus aurata (naranja de acridina, $\times$ 400): (a) tejido hepático normal de un individuo control y (b) hígado dañado de un individuo inyectado con Cd (tiempo de supervivencia <24 h). Degeneración grasa (lipidosis) mostrada como un conjunto de vacuolas pequeñas (fd), rama de la vena porta hepática (hpv), sinusoide (s), tejido pancreático normal mostrando el citoplasma de células acinares muy fluorescente (p), y degeneración grasa mostrada como una vacuola grande (vc). Las flechas indican el resquebrajamiento estructural del tejido.

progressively with $\mathrm{Cd}$ dosage, regardless of survival time (fig. 4). Hepatocyte degeneration was the most evident damage, depicting loss of cell shape and plasmatic membrane rupture. Liver sections also presented large areas of necrosis, where tissue organization was no longer perceptible, especially in individuals injected with the highest $\mathrm{Cd}$ dosages $(>6 \mu \mathrm{g} \mathrm{Cd}$ $\mathrm{g}^{-1}$ fish w.w.). Pancreatic tissue was strongly stained by AO, as expected, since the fluorochrome binds especially to nucleic acids and therefore the dense rough endoplasmatic reticulum typical of high enzyme-secretion cells (such as the acinar cells of the pancreas) emits a strong fluorescence. A prominent degeneration, more conspicuous with AO staining, of this tissue was noticeable in Cd-injected individuals, reaching the status of complete necrosis of the pancreatic tissue at higher dosages of Cd. Fluorescence microscopy using AO staining provided an overall better resolution of nuclei and cellular membranes than HE, especially at higher magnifications, and thus provided enhanced detail of hepatic damage.

No differences were observed regarding sinusoid number and structure between control and Cd-injected individuals. Overall structural analysis revealed a "foamy" structure of Cdinjected animals most likely due to an increase in intracellular storage of lipids (termed as fatty degeneration or hepatocellular lipidosis). This resulted in the proliferation of large vacuolar structures or aggregates of smaller vacuoles in hepatocytes (fig. 5). This finding is in accordance with previous studies that described hepatic vacuolation as a non-specific alteration de células con alta secreción enzimática (como las células acinares del páncreas), emite una fuerte fluorescencia. Los individuos inyectados con $\mathrm{Cd}$ mostraron una degeneración conspicua, más prominente en la tinción con NA, del tejido pancreático, presentando necrosis total de éste a mayores dosis de Cd. La microscopía de fluorescencia usando la tinción con NA en general dio una mejor resolución a los núcleos y las membranas celulares que la HE, especialmente a magnificaciones mayores, y consecuentemente proporcionó mayores detalles del daño hepático.

No se observaron diferencias en cuanto al número y la estructura de los sinusoides entre los individuos controles y los inyectados con $\mathrm{Cd}$. El análisis estructural global mostró una estructura "espumosa" de los animales inyectados con Cd probablemente debida a un incremento en el almacenamiento intracelular de lípidos (denominado degeneración grasa o lipidosis hepatocelular). Esto resultó en la proliferación de grandes estructuras vacuolares o conjuntos de vacuolas menores en los hepatocitos (fig. 5). Este resultado concuerda con estudios previos que han descrito la vacuolación hepática como una alteración no específica que sucede en peces expuestos crónicamente a metales en el agua (e.g., Arellano et al. 1999).

\section{Discusión}

En este trabajo se ha demostrado que la acumulación de $\mathrm{Cd}$ y la inducción de MTs en el hígado de peces no están linealmente correlacionadas. Más bien reflejan la capacidad 
occurring in fish chronically exposed to waterborne metals (e.g., Arellano et al. 1999).

\section{Discussion}

In this study we have demonstrated that $\mathrm{Cd}$ accumulation and MT induction in fish liver are not linearly correlated. Instead, they reflect the metabolic capability of the organ, which is progressively affected by metal dosage, as shown by the histopathological evaluation. Both liver MT and Cd show a decrease from the threshold point where the liver fails to detoxify/accumulate the metal and begins a degeneration process that ultimately leads to organ failure and animal death.

According to the present results, the time elapsed after $\mathrm{Cd}$ injection does not seem to be a crucial factor regarding the magnitude of responses and effects, unlike $\mathrm{Cd}$ dosage. This seems to be a sensible finding since $\mathrm{Cd}$ injected intraperitoneally is likely to be quickly absorbed by nearby organs and thus made readily available to affect tissues and cells. In fact, fast $\mathrm{Cd}$ absorption and intracellular mobilization have been found in liver cell cultures and single-cell organisms incubated in $\mathrm{Cd}$ solutions (Diep et al. 2005, Arunakumara et al. 2007). Conversely, exposure assays to waterborne metals depict pronounced time-dependent levels of effects and responses (Van Dyk et al. 2007), as opposed to the more dose-dependent observed in this study. It may therefore be concluded that $\mathrm{Cd}$ is a fast-acting toxicant once it has entered the organism and is absorbed by organs.

Regarding direct responses to intoxication, MT induction is independent of both the survival time elapsed after injection and liver $\mathrm{Cd}$, but it is strongly correlated to $\mathrm{Cd}$ dosage, suggesting that MT biosynthesis in liver is rapidly induced by the presence of $\mathrm{Cd}$ but is not necessarily linked to bioaccumulated $\mathrm{Cd}$ in the organ. The low correlation between MT induction and accumulated $\mathrm{Cd}$ is similar to data obtained from cultured hepatocytes exposed to the metal and is yet to be explained (Diep et al. 2005). Nevertheless, the Cd-injected individuals surviving less than $24 \mathrm{~h}$ on average induced MT at levels 2.5 -fold higher $\left(7.2 \pm 1.4 \mathrm{mg} \mathrm{g}^{-1}\right.$ liver d.w.) than the control individuals $\left(3.0 \pm 0.3 \mathrm{mg} \mathrm{g}^{-1}\right.$ liver d.w.). The fish surviving after $48 \mathrm{~h}$ induced MT 1.6- and 4.1-fold, corresponding to Cd dosages of 4.7 and $8.1 \mu \mathrm{g} \mathrm{Cd} \mathrm{g}{ }^{-1}$ fish w.w., respectively. These results are in accordance with the fast induction of other proteins involved in detoxification processes. Vaglio and Landriscina (1999), for instance, described an induction of $25 \%$ and $40 \%$ of CYP1A-related proteins in S. aurata injected with $2.5 \mu \mathrm{g} \mathrm{Cd} \mathrm{g}^{-1}$ fish w.w. after just three and four days of $\mathrm{Cd}$ injection, respectively, in a similar in vivo test.

Considering the severity of the hepatic lesions observed, especially irreversible damage such as necrosis, it should not be disregarded that liver health may compromise MT induction and metal bioaccumulation. This may explain why at higher dosages of injected $\mathrm{Cd}$ the protein was not induced and the animals were not able to accumulate the metal, since hepatic tissue sustained great damage. Organ integrity may be a very metabólica del órgano, el cual es afectado progresivamente por la dosis del metal como se muestra en la evaluación histopatológica. Tanto la MT hepática como el Cd hepático muestran una disminución a partir de cuando el hígado ya no puede destoxificar/acumular el metal, iniciando un proceso de degeneración que eventualmente conduce a la disfunción del órgano y a la muerte del animal.

Según nuestros resultados, el tiempo transcurrido después de la inyección del $\mathrm{Cd}$ no parece ser un factor importante en cuanto a la magnitud de las respuestas y los efectos, a diferencia de las dosis. Esto parece ser un resultado razonable ya que el Cd inyectado intraperitonealmente probablemente es absorbido rápidamente por los órganos cercanos, quedando disponible para afectar tejidos y células. De hecho, se ha observado una rápida absorción del $\mathrm{Cd}$ y movilización intracelular en cultivos de células hepáticas y organismos unicelulares incubados en soluciones de Cd (Diep et al. 2005, Arunakumara et al. 2007). Sin embargo, algunos ensayos de exposición a metales en el agua revelan niveles pronunciados de efectos y respuestas que dependen del tiempo (Van Dyk et al. 2007), a diferencia de lo encontrado en este estudio en cuanto a que los niveles dependen de la dosis. Por tanto, se puede concluir que el Cd es un tóxico que actúa de forma rápida cuando entra al organismo y es absorbido por los órganos.

Con respecto a las respuestas directas a la intoxicación, la inducción de MTs no depende ni del tiempo de supervivencia después de la inyección ni del nivel de Cd hepático, sino que está fuertemente correlacionada con la dosis de $\mathrm{Cd}$, lo que sugiere que la biosíntesis de las MTs en el hígado es inducida rápidamente por la presencia del $\mathrm{Cd}$ pero que no está necesariamente relacionada con la bioacumulación del $\mathrm{Cd}$ en este órgano. La baja correlación entre la inducción de MTs y el Cd acumulado concuerda con lo encontrado para hepatocitos cultivados y expuestos a este metal, pero esto aún no ha sido explicado (Diep et al. 2005). No obstante, los individuos inyectados con $\mathrm{Cd}$ que en promedio sobrevivieron menos de $24 \mathrm{~h}$ indujeron las MTs a niveles 2.5 veces mayores $\left(7.2 \pm 1.4 \mathrm{mg} \mathrm{g}^{-1}\right.$ hígado p.s.) que los controles ( $3.0 \pm 0.3 \mathrm{mg} \mathrm{g}^{-1}$ hígado p.s.). Los peces que sobrevivieron $48 \mathrm{~h}$ indujeron las MTs 1.6 y 4.1 veces, correspondiendo a dosis de $\mathrm{Cd}$ de 4.7 y $8.1 \mu \mathrm{g} \mathrm{Cd} \mathrm{g}^{-1}$ pez p.h., respectivamente. Estos resultados concuerdan con la rápida inducción de otras proteínas involucradas en los procesos de destoxificación. Vaglio y Landriscina (1999), por ejemplo, describieron una inducción de $25 \%$ y $40 \%$ de proteínas relacionadas con CYP1A en S. aurata inyectada con $2.5 \mu \mathrm{g} \mathrm{Cd}$ $\mathrm{g}^{-1}$ pez p.h. después de sólo tres y cuatro días de la inyección, respectivamente, en una prueba similar in vivo.

Considerando la severidad de las lesiones hepáticas observadas, especialmente el daño irreversible de la necrosis, no debe descartarse que la salud del hígado puede influenciar la inducción de MTs y la bioacumulación de metales. Esto podría explicar la razón por la cual la proteína no fue inducida a mayores dosis de Cd inyectado y los animales no fueron capaces de acumular el metal, dado que el tejido hepático ya se encontraba muy dañado. La integridad del órgano puede ser un 
important factor that contributes to the typical wide intrapopulation variability observed for MT induction in previous studies (e.g., Mouneyrac et al. 2002, Costa et al. 2008). This issue should be addressed, as should other biological variables, such as age and sex, known to contribute to the variability of MT induction (Hamza-Chaffai et al. 1995), for instance by surveying the population baseline liver lesions.

The present findings indicate that MT induction in the liver may be positively linked to the extent of hepatic lesions. This may be explained by the known link between antioxidant responses and MT induction, since it is likely that liver tissue degeneration produces oxidative radicals (Risso-de Faverney et al. 2001). Consequently, antioxidant mechanisms may have been triggered by functional hepatocytes, further enhancing MT transcription (Bi et al. 2004). On the other hand, Cd bioaccumulation appears to be impaired by the severity of lesions observed in fish injected with the highest $\mathrm{Cd}$ dosages. This may contribute to an overall reduction in the survival time after $\mathrm{Cd}$ injection since accumulated $\mathrm{Cd}$ may be less available to affect cellular functions.

Regarding SDS-PAGE analysis, the estimated molecular weight of $S$. aurata MT is consistent for dimeric forms of the typically $\approx 6-7 \mathrm{kDa}$ vertebrate MTs, a range in which $S$. aurata MT is included (Tom et al. 1998). The present method successfully allowed MT to be visualized without overstaining of the wide molecular-weight range peptides found in heat-treated cytosols, in spite of the low MT concentrations in cytosolic samples that resulted in dim bands. The presence of unidentified peptides in cytosolic extracts has been observed in similar studies on marine organisms that used the same extraction method (e.g., Bustamante et al. 2002, Correia et al. 2004), but these are not metal-induced and should thus not interfere with the determination of MT induction (Bebianno et al. 1992).

Our results successfully provided an insight of the mechanistics of $\mathrm{Cd}$ toxicity at tissue and biochemical levels. It should be noted that toxicological studies on aquatic organisms involving environmental contaminants in water or in sediments are typically constrained by variables such as xenobiotic bioavailability and interactions, and the characteristics of the mechanisms of apical entry and detoxification. Altogether, these are confounding factors that may impair the evaluation of the actual toxicity effects and responses, for example, by providing biomarker and bioaccumulation evaluations with a variability difficult to explain. In vivo studies such as the present experiment allow a more objective interpretation of the toxicological effects of contaminants, which is a crucial part of posterior studies involving environmental xenobiotics tested under laboratory or even field conditions. Our research has established test and biomarker techniques for $S$. aurata and provides reference information on the biomarkers studied.

\section{Acknowledgements}

The present research was approved by the Portuguese Science and Technology Foundation (FCT) and the POCTI factor importante que contribuye a la gran variabilidad intrapoblacional típica observada para la inducción de MTs en otros estudios (e.g., Mouneyrac et al. 2002, Costa et al. 2008). Es necesario atender este punto, así como otras variables biológicas, como la edad y el sexo, que contribuyen a la variabilidad en la inducción de MTs (Hamza-Chaffai et al. 1995); por ejemplo, mediante el estudio de las lesiones hepáticas ya presentes en una población.

Nuestros resultados indican que la inducción de MTs en el hígado puede estar positivamente relacionada con el grado de las lesiones hepáticas. Esto se puede explicar por la conocida asociación entre las respuestas antioxidantes y la inducción de MTs, ya que es probable que la degeneración del tejido hepático produzca radicales oxidantes (Risso-de Faverney et al. 2001). Consecuentemente, los mecanismos antioxidantes pueden haber sido desencadenados por hepatocitos funcionales, intensificando aún más la transcripción de MTs (Bi et al. 2004). Por otro lado, la bioacumulación de Cd aparentemente resulta perjudicada por la gravedad de las lesiones observadas en los peces inyectados con las dosis más altas de Cd. Esto podría contribuir a una reducción general del tiempo de supervivencia después de la inyección ya que el $\mathrm{Cd}$ acumulado puede estar menos disponible para afectar las funciones celulares.

En cuanto al análisis de SDS-PAGE, el peso molecular estimado de la MT de $S$. aurata es consistente para las formas diméricas de las MTs de vertebrados de $\approx 6-7 \mathrm{kDa}$, un intervalo en el cual se encuentra la MT de S. aurata (Tom et al. 1998). Este método permitió visualizar las MTs sin la sobretinción de los péptidos con amplio intervalo de peso molecular encontrados en los citosoles tratados térmicamente, a pesar de las bajas concentraciones de MTs en las muestras citosólicas que dieron como resultado bandas tenues. Se ha observado la presencia de péptidos no identificados en extractos citosólicos en otros estudios similares de organismos marinos utilizando el mismo método de extracción (e.g., Bustamante et al. 2002, Correia et al. 2004), pero éstos no son inducidos por los metales y por tanto no deberían de interferir en la determinación de la inducción de MTs (Bebianno et al. 1992).

Los resultados aquí presentados han dado una idea de la mecánica toxicológica del $\mathrm{Cd}$ a nivel de tejido y bioquímico. Cabe señalar que los estudios toxicológicos en organismos acuáticos que incluyen contaminantes ambientales en el agua o sedimento están típicamente limitados por variables como la biodisponibilidad y las interacciones xenobióticas, así como por las características de los mecanismos de la entrada apical y la destoxificación. En conjunto, estos son factores que se confunden y pueden perjudicar la evaluación de los efectos y las respuestas reales de la toxicidad, por ejemplo, dando evaluaciones de biomarcadores y de bioacumulación con una variabilidad difícil de explicar. Los estudios in vivo como el aquí realizado permiten llevar a cabo una interpretación más objetiva de los efectos toxicológicos de contaminantes, lo cual es crucial para estudios posteriores que involucran xenobióticos ambientales probados bajo condiciones de laboratorio y hasta 
research project (Programa Operacional Ciência, Tecnologia e Inovação, ref. POCTI/AMB 57281/104) and financed by FEDER (European Fund for Regional Development). The first author was supported by a FCT Ph.D. grant (SFRH/BD/28465/ 2006). Special thanks to M Diniz (IMAR) and J Inácio (FCT/ UNL) for their support, and to Timar/Ria Mãe (Setúbal, Portugal) for supplying the fish used in the experiment.

\section{References}

Arellano JM, Storch V, Sarasquete C. 1999. Histological changes and copper accumulation in liver and gills of the Senegalese sole, Solea senegalensis. Ecotoxicol. Environ. Saf. 44: 62-72.

Arellano JM, Ortiz JB, González de Canales ML, Sarasquete C. 2001. Histopathological alterations and induction of cytochrome P-450 $1 \mathrm{~A}$ in the liver and gills of the gilthead seabream (Sparus aurata) exposed to 2,3,7,8-tetrachlorodibenzo-p-dioxin. J. Mol. Histol. 33: $663-674$.

Arunakumara KKIU, Xuecheng Z, Song X. 2007. Comparative study on bioaccumulation of lead and cadmium by the cyanobacterium Synechocystis sp. PCC 6803 under laboratory conditions. Cienc. Mar. 33: 271-280.

Audry S, Schäfer J, Blanc G, Bossy C, Lavaux G. 2004. Anthropogenic components of heavy-metal $(\mathrm{Cd}, \mathrm{Zn}, \mathrm{Cu}, \mathrm{Pb})$ budgets in the Lot-Garonne fluvial system (France). Appl. Geochem. 19: 769-786.

Bebianno MJ, Langston WJ. 1989. Quantification of metallothioneins in marine invertebrates using differential pulse polarography. Port. Electrochim. Acta 7: 59-64.

Bebianno MJ, Langston WJ, Simkiss K. 1992. Metallothionein induction in Littorina littorea (Mollusca: Prosobranchia) on exposure to cadmium. J. Mar. Biol. Assoc. UK 72: 329-342.

Bi Y, Palmiter D, Wood KM, Ma Q. 2004. Induction of metallothionein I by phenolic antioxidants requires metalactivated transcription factor 1 (MTF-1) and zinc. Biochem. J. 380: 695-703.

Bustamante P, Cosson RP, Gallien I, Caurant F, Miramand P. 2002. Cadmium detoxification processes in the digestive gland of cephalopods in relation to accumulated cadmium concentrations. Mar. Environ. Res. 53: 227-241.

Candiano G, Bruschi M, Musante L, Santucci L, Ghiggeri GM, Carnemolla M, Orecchia P, Zardi L, Righetti PG. 2004. Blue silver: A very sensitive colloidal Coomassie G-250 staining for proteome analysis. Electrophoresis 25: 1327-1333.

Carvalho CS, de Araujo HSS, Fernandes MN. 2004. Hepatic metallothionein in a teleost (Prochilodus scrofa) exposed to copper at pH 4.5 and pH 8.0. Comp. Biochem. Physiol. B 137: 225-234.

Chowdhury MJ, Pane EF, Wood CM. 2004. Physiological effects of dietary cadmium acclimation and waterborne cadmium challenge in rainbow trout: Respiratory, ionoregulatory, and stress parameters. Comp. Biochem. Physiol. C 139: 163-173.

Clesceri LS, Greenberg AE, Eaton AD. 1999. Standard Methods for Examination of Water \& Wastewater, 20th ed. American Public Health Association, Baltimore, $1220 \mathrm{pp}$.

Correia AD, Sousa A, Costa MH, Moura I, Livingstone DR. 2004. Quantification of metallothionein expression in whole body Gammarus locusta (Crustacea: Amphipoda) using differential pulse polarography. Toxicol. Environ. Chem. 86: 23-36.

Costa PM, Costa MH. 2007. Genotoxicity assessment in fish peripheral blood: A method for a more efficient analysis of micronuclei. J. Fish Biol. 71A: 148-151. de campo. Este trabajo ha establecido técnicas de prueba y de biomarcadores para $S$. aurata y proporciona información de referencia sobre los biomarcadores estudiados.

\section{Agradecimientos}

Este trabajo fue aprobado por la Fundación de Ciencia y Tecnología de Portugal (FCT) y el proyecto de investigación POCTI (Programa Operacional Ciência, Tecnologia e Inovação, ref. POCTI/AMB 57281/104) y financiado por el Fondo Europeo de Desarrollo Regional (FEDER). El primer autor recibió una beca doctoral de FCT (SFRH/BD/28465/2006). Un agradecimiento especial a M Diniz (IMAR) y J Inácio (FCT/ UNL) por su apoyo, y a Timar/Ria Mãe (Setúbal, Portugal) por proporcionar los peces utilizados en este experimento.

Traducido al español por Christine Harris.

Costa PM, Repolho T, Caeiro S, Diniz ME, Moura I, Costa MH. 2008. Modelling metallothionein induction in the liver of Sparus aurata exposed to metal-contaminated estuarine sediments. Ecotoxicol. Environ. Saf. 71: 117-124.

Diep PTN, Denizeau F, Jumarie C. 2005. Kinetics of the early subcellular distribution of cadmium in rat hepatocytes. BioMetals 18: 255-267.

Fernández N, Cesar A, González M, DelValls TA. 2006. Level of contamination in sediments affected by the Prestige oil spill and impact on the embryo development of the sea urchin. Cienc. Mar. 32: 421-427.

Hallare AV, Shirling M, Luckenbach T, Köhler HR, Triebskorn R. 2005. Combined effects of temperature and cadmium on developmental parameters and biomarker responses in zebrafish (Danio rerio) embryos. J. Therm. Biol. 30: 7-17.s

Hamza-Chaffai A, Cosson RP, Amiard-Triquet C, El-Abed A. 1995. Physico-chemical forms of storage of metals $(\mathrm{Cd}, \mathrm{Cu}$ and $\mathrm{Zn})$ and metallothionein-like proteins in gills and liver of marine fish from the Tunisian coast: Ecotoxicological consequences. Comp. Biochem. Physiol. C 111: 329-341.

Handy RD, Runnals T, Russel PM. 2002. Histopahologic biomarkers in three spined sticklebacks, Gasterosteus aculeatus, from several rivers in southern England that meet the freshwater fisheries directive. Ecotoxicology 11: 467-479.

Jones I, Kille P, Sweeney G. 2001. Cadmium delays growth hormone expression during rainbow trout development. J. Fish. Biol. 59: $1015-1022$.

Laemmli UK. 1970. Cleavage of structural proteins during the assembly of the head of bacteriophage T4. Nature 227: 680-685.

Majumder S, Ghoshal K, Summers D, Bai S, Datta J, Jacob ST. 2003. Chromium (IV) down-regulates heavy-metal induced metallothionein gene transcription by modifying transactivation potencial of the key transcription factor, metal-responsive transcription factor 1. J. Biol. Chem. 278: 26216-26226.

Margoshes M, Vallee BL. 1957. A cadmium protein from equine kidney cortex. J. Am. Chem. Soc. 79: 4813-4819.

Martínez G, Senior W, Márquez A. 2006. Heavy metal speciation in the surface water dissolved fraction of the low watershed and plume of the Manzanares River, Sucre State, Venezuela. Cienc. Mar. 32: 239-257.

Martoja R, Martoja M. 1967. Initiation aux Tecniques de l'Histologie Animal. Masson \& Cie., Paris, 345 pp. 
Morales-Caselles C, Jiménez-Tenorio N, Riba I, Sarasquete C, DelValls TA. 2007. Kinetic of biomarker responses in juveniles of the fish Sparus aurata exposed to contaminated sediments. Environ. Monit. Assess. 131: 211-220.

Mouneyrac C, Amiard JC, Amiard-Triquet C, Cottier A, Rainbow PS, Smith BD. 2002. Partitioning of accumulated trace metals in the talitrid amphipod crustacean Orchestia gammarellus: A cautionary tale on the use of metallothionein-like proteins as biomarkers. Aquat. Toxicol. 57: 225-242.

Palecek E, Pechan Z. 1971. Estimation of nanogram quantities of proteins by pulse polarographic techniques. Anal. Biochem. 42: 59-71.

Prego R, Cobelo-García A, Marmolejo-Rodríguez J, SantosEcheandía J. 2006. Trace elements in the Prestige fuel-oil spill: Levels and influence on Laxe Ria sediments (NW Iberian Peninsula). Cienc. Mar. 32: 179-186.

Risso-de Faverney C, Devaux A, Lafaurie M, Girard JP, Bailly B, Rahmani R. 2001. Cadmium induces apoptosis and genotoxicity in rainbow trout hepatocytes through generation of reactive oxygen species. Aquat. Toxicol. 53: 65-76.

Romero-Isart N, Vašák M. 2002. Advances in the structure and chemistry of metallothioneins. J. Inorg. Biochem. 88: 388-396.

Sheskin FJ. 2000. Handbook of Parametric and Nonparametric Statistical Procedures. 2nd ed. Chapman \& Hall, Boca Raton, $982 \mathrm{pp}$.

Singhal RK, Anderson ME, Meister A. 1987. Glutathione, a first line of defense against cadmium toxicity. FASEB J. 1: 220-223.
Suzuki JS, Kodama N, Molotov A, Aoki E, Tohyama C. 1998. Isolation and identification of metallothionein isoforms (MT-1 and MT-2) in the rat testis. Biochem. J. 334: 695-701.

Tom M, Moran O, Jabukov E, Cavari B, Rinkevitch B. 1998. Molecular characterization of metallothionein-cDNA of Sparus aurata used for detecting heavy metal pollution along the Mediterranean coast of Israel. Mar. Pollut. Bull. 36: 131-137.

Tom M, Chen N, Segev M, Herut B, Rinkevitch B. 2004. Quantifying fish metallothionein transcript by real time PCR for its utilization as an environmental biomarker. Mar. Pollut. Bull. 48: 705-710.

Vaglio A, Landriscina C. 1999. Changes in liver enzyme activity in the teleost Sparus aurata in response to cadmium intoxication. Ecotoxicol. Environ. Saf. 43: 111-116.

Van Dyk JC, Pieterse GM, Van Vuren JHJ. 2007. Histological changes in the liver of Oreochromis mossambicus (Cichlidae) after exposure to cadmium and zinc. Ecotoxicol. Environ. Saf. 66: 432-440.

Waeles M, Riso RD, Maguer JF, Le Corre P. 2004. Distribution and speciation of dissolved cadmium and copper in the Loire Estuary and North Biscay continental shelf, France. Estuar. Coast. Shelf Sci. 59: 49-57.

Wormser U, Ben Zakine S, Nyska A. 1990. Cadmium-induced metallothionein synthesis in the rat liver slice system. Toxicol. In Vitro 4: 791-794.

Žikić RV, Štajn AŠ, Pavlović SZ, Ognjanović BI, Saićić ZS. 2001. Activities of superoxide dismutase and catalase in erythrocytes and plasma transaminases of goldfish (Carassius auratus gibelio Bloch.) exposed to cadmium. Physiol. Res. 50: 105-111.

Recibido en febrero de 2008;

aceptado en julio de 2008. 